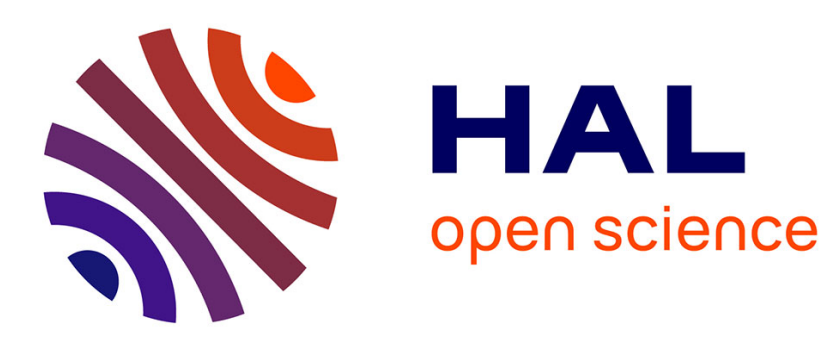

\title{
Les chemins de l'intransigeance. Radicalité catholique et engagement politique à Toulouse lors des guerres de religion \\ Pierre-Jean Souriac
}

\section{- To cite this version:}

Pierre-Jean Souriac. Les chemins de l'intransigeance. Radicalité catholique et engagement politique à Toulouse lors des guerres de religion. Moreana, 2006, 43, pp.82 - 114. 10.3366/more.2006.43.2-3.8 . hal-01587085

\section{HAL Id: hal-01587085 \\ https://hal.science/hal-01587085}

Submitted on 13 Sep 2017

HAL is a multi-disciplinary open access archive for the deposit and dissemination of scientific research documents, whether they are published or not. The documents may come from teaching and research institutions in France or abroad, or from public or private research centers.
L'archive ouverte pluridisciplinaire HAL, est destinée au dépôt et à la diffusion de documents scientifiques de niveau recherche, publiés ou non, émanant des établissements d'enseignement et de recherche français ou étrangers, des laboratoires publics ou privés. 


\section{Les chemins de l'intransigeance \\ Radicalité catholique et engagement politique à Toulouse lors des guerres de Religion}

\section{Pierre-Jean Souriac}

Maître de conférences - Université Jean Moulin-Lyon III

Chercheur au LARHRA

Publication dans Moreana, 2006.

Toulouse, le 7 janvier 1589 : le vicaire général de l'archevêque faisait son entrée au consistoire de l'Hôtel de ville, la salle du conseil, et tenait aux magistrats municipaux de Toulouse le discours suivant :

[L'évêque et le clergé toulousain] sont extremement marris de venyr ceans represanter a ceste compaignye le deplorable acte et esgorgement faict es personnes de messieurs le duc de Guyse et cardinal son frere en la ville de Bloys, quy estoient les protecteurs et soutien de notre saincte foy et religion catholicque, appostolique et romayne en ce royaulme comme ledict sieur duc a monstré par effaict l'annee derniere, ayant combatu et vaincu en champ de batailhe l'hereticque estrangier', qu'il est fermement a croyre que pour ses merites il est avec le nombre des sainctz, martirs devant Dieu, comme de mesme ledict feu sieur cardinal, qu'il y a occasions [que] les chapitres et clergé s'assemblent pour adviser a notre conservation, car il est a craindre qu'il y ayt de grandes intelligences en toutes les principalles villes de ce royaulme pour exterminer les bons catholicques, se saisir et emparer desdites villes pour les rendre en fin hereticques. ${ }^{2}$

Cette interpellation du corps de ville par le clergé toulousain à la veille du basculement ligueur de la capitale languedocienne n'était alors qu'une énième reprise d'un discours rabattu, reflet de l'opinion des citadins qui avaient fait le choix de l'intransigeance religieuse au temps des guerres de Religion. Les ressorts en étaient toujours les mêmes, à la fois conjoncturels et structurels. Leur réactualisation venait d'un choc affectif, ici la perte d'un des leaders charismatiques du mouvement ultra-catholique français sur ordre d'Henri III. L'événement devenait l'objet de mises en récit à partir d'informations qui circulaient au sein du milieu confessionnel par la rumeur et par les correspondances privées, pour atteindre les périphéries du royaume selon des versions très éloignées du discours officiel. Enfin, l'angoisse quasiobsessionnelle des protagonistes de ces temps troublés prenait corps dans un sentiment de menace exacerbé par le contexte de tensions politico-religieuses. Cette menace était ressentie à la fois pour sa propre survie et pour la défense de sa foi, celle que l'on estimait être la seule source de salut. En 1589, l'annonce de l'assassinat de Blois suffit alors à faire sortir Toulouse de son quotidien pour entrer dans la spirale de la révolte au nom de la Ligue catholique. Dans la collectivité urbaine aux prises avec la guerre, cette ultime étape dans le parcours de l'intransigeance religieuse réveilla le dialogue imaginaire apparu depuis 1562 entre ceux qui se prétendaient être les gardiens d'une cité idéale voulue par Dieu et des adversaires plus ou moins fantasmés, situés entre l'hérétique et le barbare, dont l'objectif était d'agir à la moindre occasion pour exterminer les fidèles citadins. Toulouse se perçut à cette époque comme une citadelle assiégée par des hordes d'hérétiques et orienta sa vie politique sur cette exigence de survie aussi bien que sur celle de sainteté. Le basculement ligueur constitua l'achèvement du processus, mais il eut une histoire politique, confessionnelle et partisane au sein de cette ville du Sud Ouest. C'est cette histoire qu'il convient de retracer.

Ville de 45 à 50000 habitants comptant une municipalité prestigieuse, le capitoulat, ville également siège d'un Parlement, le deuxième du royaume, et ville en plein essor économique au $\mathrm{XVI}^{\mathrm{e}}$ siècle grâce à la culture du pastel, Toulouse apparaissait à bien des contemporains de ces

\footnotetext{
124 novembre 1587 : victoire du duc Henri de Guise sur les reîtres allemands à Auneau, près de Chartres.

2 Arch. mun. Toulouse, BB 16, f $229 \mathrm{v}$ : délibérations du conseil général de la ville de Toulouse - 7 janvier 1589.
} 
temps troublés comme la seconde ville du royaume ${ }^{3}$. Elle se situait en outre au cœur d'un territoire traversé de frontières confessionnelles autour desquelles s'organisait l'affrontement catholico-protestant. La région de Montauban, de Castres, une partie du Lauragais autour de Puylaurens, le comté de Foix, étaient des points forts du protestantisme régional. Face à eux, Toulouse, Albi, le Comminges faisaient figure de fiefs d'un catholicisme particulièrement virulent. D'autre part, d'un point de vue stratégique, les plaines fertiles de la Garonne et du Lauragais, les collines albigeoises, le contrôle de leur production et de leur trafic s'étaient rapidement avérés très précieux pour des partis en guerre qui devaient vivre sur les pays. Toulouse était ainsi au cœur d'une région où les oppositions étaient vécues au quotidien dans une dimension exclusivement régionale : à quelques exceptions près, pas de grandes armées royales ou partisanes, pas de grandes batailles, et surtout une domination de chefs de guerre locaux relativement éloignés du centre parisien. La ville fut alors en état de veillée d'armes quasi permanent sur près de 40 ans, du basculement dans la guerre civile en mai 1562 à la pacification régionale par l'Edit de Folembray en janvier 1596. Mais cette fièvre militaro-religieuse ne se transforma jamais en véritable aventure guerrière. Toulouse attendit la guerre, mais ne la fit que peu. Tel le rivage des Syrthes ou le désert des Tartares, l'horizon toulousain fut davantage peuplé de fantômes protestants que de véritables soldats, objets fantasmatiques entretenant la crainte d'une attaque imminente, projection des propres visions d'angoisse d'un milieu catholique aux mains tachées de sang.

Le parcours partisan toulousain s'orienta très tôt vers l'intransigeance, au sens d'un rejet violent de l'altérité : si l'Eglise réformée réussit à s'implanter dans la ville autour de 1560, une semaine de combats de rue entre tenants des deux confessions suffit à chasser définitivement hors les murs les disciples de Calvin en mai 1562. Dès lors, la municipalité toulousaine fit le choix de la cause romaine en participant activement à l'effort de guerre méridional, par sa puissance financière et humaine, ainsi que par son rôle de bastion militaire imprenable par les armées du temps. Se présentant comme fidèle à la cause royale, elle sauta le pas de la révolte en janvier 1589, suite à l'assassinat des Guise à Blois. Adhérant à la Sainte Union jurée initialement à Paris, elle connut une expérience originale avec un gouvernement quasi-autonome, avant d'être intégrée au mouvement ligueur languedocien de 1590 à 1596. Nous aimerions montrer ici comment le choix de l'intransigeance catholique s'imposa comme la voie de salut de la cité dans ces temps troublés, comment un milieu municipal d'abord minoritaire parvint à imposer ses vues à la communauté urbaine au point de construire un véritable consensus confessionnel autour de la radicalité religieuse, et enfin, comment la question catholique devint le moteur d'une politique municipale, jusqu'à risquer le crime de lèse-majesté par la désobéissance au souverain.

\section{Rejeter 1'hérétique, purifier la ville}

Les débuts de la Réforme à Toulouse ne sont pas très bien connus : ils remontent aux premières sympathies que lui portèrent quelques membres isolés de l'université toulousaine, foyer d'humanisme et par corrélation, foyer d'évangélisme et de pensées nouvelles en matière religieuse ${ }^{4}$. Jean de Boyssonné, originaire de la ville, y enseigna dans la première moitié du XVI siècle ; Etienne Dolet passa par Toulouse au début des années 1530 et dut s'en exiler pour accusation d'hérésie en 1532 ; Jean de Caturce, bachelier en droit civil, fut brûlé vif la même année. Autant de figures qui attestent du bouillonnement intellectuel et religieux qui agitait l'institution et sa ville. L'Eglise réformée proprement dite semble avoir été fondée à Toulouse

\footnotetext{
${ }^{3}$ Michel Taillefer, Vivre à Toulouse sous l'Ancien Régime, Paris, Perrin, 2000.

${ }^{4}$ Henri Gilles, Université de Toulouse et enseignement du droit XIII ìme-XVI ime siècles, Toulouse, SEDUSS, 1992 ; Antonin Deloume, Histoire sommaire de la Faculté, Toulouse, Privat, 1905.
} 
vers 1558 , et véritablement dressée entre 1560 et $1561^{5}$. Sa première manifestation publique eut lieu au cours de l'hiver 1561, lorsque les psaumes commencèrent à sortir des maisons particulières. Le jour des Rameaux 1561, les réformés toulousains osèrent enfin quitter un des collèges de la ville qui abritait leur culte clandestin pour sillonner les rues en entonnant triomphalement et en français ces hymnes bibliques. Peu après, c'est un des prédicateurs catholiques des plus virulents, le cordelier Melchior Flavin, qui fut apostrophé lors d'un prêche dans une église toulousaine, traité de menteur par un auditeur, lui-même immédiatement saisi et tué par la foule assemblée. Au tournant de la décennie 1560, cette Eglise réformée toulousaine en voie d'affirmation comptait environ 4000 personnes dans une ville de 50000 âmes, soit une minorité dont la présence ne pouvait plus passer inaperçue 6 .

Face à l'émergence de cette nouvelle confession, le milieu catholique s'organisa très rapidement autour d'un certain nombre de conseillers du Parlement de Toulouse qui usèrent de tous les moyens légaux pour venir à bout de ces nouveaux hérétiques. Une chambre ardente fut instituée avant même l'affaire des Placards, en 1532, et Rabelais disait d'elle qu'elle s'employait à faire brûler les régents d'université tout vifz. comme harans soretz. vigueur contre les assemblées et le port d'armes, en pourchassant les livres interdits et les manifestations religieuses suspectes, les officiers du Parlement lancèrent des poursuites à chaque rumeur de conventicule protestant aussi bien à Toulouse que dans ses environs. Le clergé et un groupe actif de notables urbains lui emboîtèrent le pas à partir de 1561, dénonçant sur la place publique la nouvelle religion, source de discorde introduite par ces nouveaux chrétiens dans la communauté civique ${ }^{8}$. L'argument de la paix civile fut alors accaparé par les milieux catholiques pour promouvoir l'idée d'exclusivisme confessionnel. Ces tenants d'une confession unique dans la cité assimilaient l'altérité religieuse à un différend inconciliable entre les habitants, anticipation d'une ruine certaine dont le chemin était ponctué de ces querelles quotidiennes. Au sein de la bonne ville conçue comme une autonomie locale s'autoadministrant pour le service de Dieu, du roi, et du citadin, la division de foi ne pouvaient manquer de conduire à l'éclatement social de la collectivité et donc à la dissolution de cette identité politique ${ }^{9}$. A cela, les réformés toulousains arguaient de la liberté de conscience et de culte pour ramener le calme et éviter la désunion des citadins, utilisant comme leurs adversaires l'argument de l'unité civique pour trancher la question religieuse : pour eux, admettre un culte légal revenait à pacifier les humeurs. Catherine de Médicis fit ce choix par une tentative de coexistence entre les deux communautés. Elle imposa l'Edit de Janvier 1562 qui autorisait notamment l'installation d'un lieu de culte dans les faubourgs de Toulouse. Contrairement à ses attentes, plutôt que d'apaiser les tensions, cette décision politique conduisit, dans un redoutable systématisme, à une polarisation partisane dont la conséquence fut la guerre civile.

\footnotetext{
${ }^{5}$ Baum et Cumiz (ed.), Histoire ecclésiastique des Eglises Réformées au royaume de France, Paris, 1885, t. I, p. 182 et 373.

${ }^{6}$ Joan Davies, "Persecution and Protestantism : Toulouse, 1562-1575", The historical Journal, 1979, n 22, p.33 ; Mark Greengrass, "The anatomy of religious riot in Toulouse in may 1562", Journal d'Histoire ecclésiastique, 1983, n 34, p. 372.

${ }^{7}$ François Rabelais, Pantagruel, Paris, Gallimard, coll. "La Pléiade", 1994, p. 230.

${ }_{8}^{8}$ Pierre-Jean Souriac, "Les fantasmes d'une menace. La peur d'une frontière intérieure à Toulouse au temps des guerres de Religion", Les frontières religieuses - actes du colloque organisé par le Centre Culturel Gulbenkian et l'Université Paris $I V$, juin 2004, à paraître.

${ }^{9}$ Arch. mun. Toulouse, BB 12, $\mathrm{f}^{\circ} 131$ : lettre des ecclésiastiques de Toulouse à Catherine de Médicis - 8 septembre 1561 : Et pour aultant, Madame, que nous sommes asseurez que votre premier desir est de veoir la fin des troubles, divisions et scismes qui sont en ce royaulme tres chrestien, nous vous supplions tres humblement prendre de bonne part et recepvoir l'advertissement et tres bumble supplication que nous vous faisons pour la tranquilité, union et pacification de ceste votre ville de Tholouze et tout votre pays adjacent et vouloir de votre benigne grace, bumanité et bonté, les exempter de semblables desordres [c'est-à-dire le culte réformé] que se commectent journellement esdites villes de Montauban, Lectoure, Lavaur, Castres et aultres et en repoz de noz. espritz, nous continuerons prier le createur pour la prosperité et felicité de votre magesté en votre esglise de Tholouze.
} 
D'un point de vue très concret, les différents chroniqueurs présentent la période qui court de janvier à mai 1562 comme un temps d'armement intensif des notables toulousains ${ }^{10}$. Dans les hôtels particuliers des conseillers catholiques ou des magistrats réformés, on entassait poudre, armes à feu portatives ou armes blanches; des capitaines sillonnaient les rues pour rassembler des compagnies de fortune et chaque célébration catholique, procession, enterrement, prêche, chaque culte protestant étaient l'occasion de micro-affrontements qui montaient progressivement en intensité. Le phénomène le plus grave pour la stabilité de l'ordre urbain résida dans la confessionnalisation des rapports de force traditionnels. Le Parlement, malgré ses composantes modérées, passa sous la coupe du milieu catholique le plus radical alors que le corps de ville, le capitoulat, au positionnement moins tranché, fut accusé de défendre les réformés. Se rejouait alors l'affrontement habituel et récurrent qui opposait dans l'enceinte toulousaine la cour souveraine au corps de ville : la première prétendait pouvoir mettre en tutelle le second au nom de l'autorité royale qu'elle représentait, alors que le second déniait ce droit à la première en vertu de ses privilèges et franchises ${ }^{11}$. La question religieuse se surimposait alors à des clivages bien plus profonds, faisant des uns les défenseurs du catholicisme et des autres les diffuseurs du calvinisme, le tout dans le strict respect de rôles antagonistes distribués avant les troubles. Or, de tels engagements religieux étaient nécessairement plus complexes, chacune de ces institutions comptant des individus des deux bords, mais la radicalité confessionnelle faisait disparaitre la moindre nuance et investissait sans état d'âme un terrain de lutte urbaine bien balisé. L'opposition institutionnelle servait d'exutoire à l'opposition religieuse dans des processus d'instrumentalisation réciproques et concomitants.

Le point critique fut atteint dans la nuit du 11 au 12 mai 1562 : ce soir là, une petite troupe de réformés menés par un des pasteurs de la ville entra dans la maison commune et s'en saisit militairement. De la sorte, ce coup de théâtre permit à la minorité réformée de faire à la fois main basse sur l'arsenal et sur le lieu du pouvoir municipal, dans l'espoir de faire basculer la ville entière dans l'orbite du parti protestant ${ }^{12}$. L'intrusion de la violence partisane eut le mérite de clarifier les rapports de force en imposant aux adversaires une nécessaire organisation. La résistance catholique fut logiquement initiée puis encadrée par les officiers du Parlement de Toulouse. Alors que Jean de Mansencal, premier président ${ }^{13}$, était accusé de mollesse face au coup de main militaire des réformés, alors que le milieu modéré se réveillait au petit matin désarçonné par la nouvelle, un syndicat particulièrement actif semble s'être imposé au sein de la cour souveraine ${ }^{14}$. A sa tête, le milieu catholique le plus intransigeant se mit alors à dicter ses décisions à l'ensemble des catholiques qui le suivit au nom de la défense de la foi et du roi. Sous couvert d'unanimité, une minorité de combat venait de se rendre maitre de l'institution, prise de pouvoir savamment

\footnotetext{
10 Arch. mun. Toulouse, BB 104, $\mathrm{f}^{\circ}$ 405r-v. ; BB 11, $\mathrm{f}^{\circ}$ 259r ; Georges Bosquet, Histoire de M.G. Bosquet sur les troubles advenus en la ville de Toulouse l'An 1562, Toulouse, R. Colomiez, 1595, p. 15 [édition française établie à partir d'une version latine publiée en 1563 et à ce jour perdue] ; Henri de La Popelinière, L'bistoire de France, Abraham, 1581, f 311v-312r ; "Relation de l'émeute arrivée à Toulouse" dans L.Cimber, F. Danjou, Archives curieuses de l'bistoire de France depuis Louis XI jusqu'à Louis XVIII, Paris, Beauvais, 1835, t. IV, p. 345-356; Mark Greengrass, "The anatomy of religious riot in Toulouse in may 1562", Journal d'histoire ecclésiastique, 1983, n³4, p. 376.

11 Thierry Mailles, "Les relations politiques entre le Parlement de Toulouse et les capitouls, de 1540 environ à 1572", dans Jacques Poumarède, Jack Thomas, Les Parlements de Province, pouvoirs, justice et société du XV an XVIII siècle, Toulouse, Framespa, 1996, p. 511 ; André Viala, Le parlement de Toulouse et l'administration royale lä̈que, 1420-1525 environ, Albi, impr. des Orphelins apprentis, 1953, 2 vol., p. 15 ; Robert A. Schneider, Public life in Toulouse, $1463-1789$. From municipal republic to cosmopolitan city, New York, C.U.P., 1989.

12 Pierre-Jean Souriac, "Les "urgeans" affaires de la ville. Défendre Toulouse durant la première guerre de religion, 15621563", Revue d'bistoire urbaine, n³, juin 2001, p. 39-65.

13 Jean de Mansencal : né à Bazas en 1521, et mort à Toulouse le 29 octobre 1562 ; reçu président au Parlement de Toulouse en 1537, il obtint la charge de premier président du Parlement le 7 mars 1539 ; lors des émeutes de 1562, un de ses fils combattait dans les rangs protestants, et lui-même détenait des armes dans son hôtel, armes dont se saisirent les catholiques.

${ }^{14}$ Mark Greengrass, "anatomy of religious riot... ", op. cit., p. 380.
} 
préparée et qui n'attendait que l'occasion propice pour se réaliser. Nicolas Latomy ${ }^{15}$ et Antoine de Paulo $^{16}$ furent les magistrats les plus impliqués : en étant tous deux présidents de la cour, leur autorité, leur éloquence et leur réseau relationnel au sein de la basoche suffirent à leur assurer un contrôle unilatéral des décisions d'urgence. Ce syndicat prit alors une série de mesures pour lui assurer le contrôle de la ville : il appela la noblesse catholique du plat pays toulousain à venir se battre dans sa capitale, il créa un trésorier militaire chargé de financer l'armée catholique ainsi mobilisée et surtout, il condamna les capitouls en place, les destitua et en nomma huit nouveaux à sa convenance. Les notables municipaux portés au pouvoir en décembre 1561 payèrent alors au prix fort l'audace protestante ${ }^{17}$. Ils comptaient pourtant dans leur rang essentiellement des modérés soucieux de préserver la paix civile en faisant respecter les édits de coexistence publiés par Catherine de Médicis. Sur les huit magistrats, deux ou trois étaient probablement calvinistes, guère plus, mais leur place institutionnelle dans la cité les fit taxer collégialement de protestantisme $^{18}$. Se greffant sur la revitalisation de l'opposition traditionnelle entre institutions toulousaines, le coup de main réformé porté contre l'Hôtel de ville servit de prétexte aux officiers catholiques du Parlement pour condamner l'ensemble du corps consulaire. Il servit également d'argument pour introduire dans les rouages municipaux des hommes proches de la cour, et ainsi, sinon mettre en tutelle, du moins engager une politique de coopération imposée entre les deux institutions civiles les plus puissantes de la cité. Minoritaires et coupés de soutiens extérieurs, les réformés ne purent tenir la place plus d'une semaine ; à l'issue de six jours de combats acharnés, ils durent abandonner la ville, non sans laisser de nombreux morts aux pieds des remparts toulousains. Plus jamais un membre de la minorité calviniste n'occupa une charge urbaine, plus jamais les protestants eurent le droit d'avoir un culte dans l'enceinte toulousaine avant le XIX ${ }^{\mathrm{e}}$ siècle.

Dès lors, la faction catholique la plus intransigeante siégea à la fois au Parlement et à l'Hôtel de ville, faisant disparaittre du même coup les tensions institutionnelles et religieuses. La confessionnalisation des tensions politiques avait ainsi abouti au triomphe d'un groupe sur l'autre, ce qui n'avait jamais pu être le cas au préalable. Apparut alors au grand jour un milieu politique déterminé à faire de la ville une citadelle du catholicisme, au service de Dieu et du roi, au service de salut de la communauté toute entière. En partant des individus institués par le Parlement entre 1562 et 1563 , lors de cette première guerre de Religion, on peut déceler l'existence d'un groupe porteur d'une idéologie de radicalité catholique dont l'activisme put s'épanouir au cours de cette

\footnotetext{
${ }^{15}$ Nicolas Latomy [Lathomy] : reçu second président du Parlement de Toulouse le 27 juillet 1557 ; il engagea la cour souveraine dans la résistance au coup de main protestant, puis présida l'ensemble des conseils généraux de la ville de Toulouse entre 1566 et 1570 ; il fut accusé d'avoir cautionné les massacres protestants d'octobre 1572 à Toulouse, car des témoins disent l'avoir vu accompagner les assassins vers le palais ; il est mort le 9 mars 1587.

16 Antoine de Paulo, sieur de Cépet, La Fitte, Vigordane, La Faurie, Roques, Grandval : il fut reçu conseiller au Parlement de Toulouse le 18 août 1537, puis cinquième président le 20 novembre 1554 ; il était second président du Parlement en mai 1562 lors des émeutes de la ville, catholique très actif dès la première guerre civile, et de manière encore plus affirmée entre 1567 et 1570 ; il fut un des trois prétendants à la succession de Jean de Mansencal à la charge de premier président en 1563, soutenu par les ducs de Mayenne et de Guise auprès du souverain ; il mourut avant le 8 juillet 1573 .

${ }^{17} \mathrm{Au}$ début du printemps 1562, une grande partie des villes françaises du centre et du sud passèrent sous le contrôle du parti protestant organisé et révolté derrière le prince Louis de Condé : Janine Garrisson évoque une véritable tornade, un raz de marée qui a montré l'étendue de la puissance réformée sur le royaume [Janine Garrisson, Protestants du Midi, 1559-1598, Toulouse, Privat, 1980, p. 168].

${ }^{18}$ Ces capitouls étaient: Adémar Mandinelli [capitoulat de la Daurade], Pierre Hunaud seigneur de Lanta [capitoulat de Saint-Etienne], Pierre Assézat [capitoulat du Pont-Vieux], Pierre Du Cèdre [capitoulat de La Pierre-Saint Giraud], Guillaume Dareau [capitoulat de la Dalbade], Antoine de Ganelon [capitoulat de Saint-Pierre-des-Cuisines], Olivier Pastoreau [capitoulat de Saint-Barthélemy], Arnaud de Vignes sieur de Montesquieu [capitoulat de Saint-Sernin]. Ils furent tous condamnés par contumace et pendus en effigie sur ordre du Parlement. Seul Adémar Mandinelli fut arrêté après la défaite protestante, et mourut sur l'échafaud, sa tête demeurant affichée sur la porte de l'hôtel de ville à côté d'une plaque de marbre portant l'arrêt de condamnation pour trahison. Les sept autres qui avaient fui la ville, obtinrent du roi et des édits de pacification le droit de regagner la ville, mais eurent du mal à passer outre l'hostilité des officiers du Parlement.
} 
crise. Ce sont d'abord deux frères, les Delpuech, Pierre et François, riches bourgeois toulousains en marge du pouvoir jusque-là. Le premier, en lien étroit avec le milieu Guisard parisien, s'était fait remarquer courant avril 1562 en rassemblant chez lui des bourgeois de la ville pour leur faire part d'une lettre du duc de Guise l'avertissant de la décision du Parlement de Paris de faire exterminer les protestants de la capitale ${ }^{19}$. Même si ce courrier ne se fondait que sur une fausse rumeur, Pierre Delpuech appelait les Toulousains au massacre et recrutait des hommes en armes pour le moment inexorable où il faudrait en venir aux mains. Ce fut ce même bourgeois qui, rentrant de Paris en octobre 1572, prétendit avoir reçu une lettre du roi ordonnant de massacrer les protestants toulousains ${ }^{20}$. Mêmes contextes de crise, mêmes procédures, et mêmes appels à la violence. Ce n'est donc pas un hasard s'il fut nommé capitoul par le Parlement en mai 1562, au moment de l'insurrection protestante. Son frère fut quant à lui capitoul en 1568, année de la reprise de la guerre civile, ce qui avait justifié l'élection d'un corps municipal de combat à l'instigation du Parlement ${ }^{21}$. A côté d'eux, tout un groupe s'investit dans la faction radicale toulousaine qui leur permit de se maintenir au pouvoir par une charge municipale ou une influence directe sur le corps de ville : Guillaume de Lalaine, capitoul en 1562, le fut à nouveau en 1570 lorsque l'amiral de Coligny approchait avec une armée de 10000 protestants ; Etienne Mazade, lui aussi capitoul en 1562, le fut à nouveau en 1569, en pleine guerre, ou encore Raymond Faure, capitoul en 1562, et une seconde fois en 1570. Jean d'Alies et Jean Roquier furent eux aussi dans ce cas. Notons encore Jean-Etienne Duranti, futur procureur général du Parlement, futur premier président, impliqué dans les massacres de la Saint-Barthélemy, capitoul en 1563. Cette poignée d'individus appartenait en outre aux élites financières de la cité, prenant part en bonne place dans les emprunts citadins, dans les impôts extraordinaires levés en raison des conflits et dans les avances d'argent nécessaires à l'effort de guerre ${ }^{22}$. Il s'agissait alors d'un groupe de bourgeois toulousains bien implantés dans la ville, relativement prospères, prêts à se saisir des rênes du pouvoir dans des phases critiques, prêts à payer de leurs deniers personnels les exigences de la guerre. Si la violence de leurs actions a discrédité ces hommes, leur investissement dans la vie politique et financière de la cité a pour le moins montré leur sincérité.

Milieu proche du Parlement de Toulouse, il entreprit dès lors une politique de coopération avec les officiers de justice dans les prises de décision urbaine. A la lecture des délibérations municipales pour la décennie 1562-1570, on ne peut que constater une présence accrue des conseillers et présidents du Parlement aux conseils de ville réglant les questions de mise en défense, notamment dans les phases d'entrée en guerre nécessitant la plus grande réactivité urbaine $^{23}$. En droit, les officiers du Parlement étaient tenus de présider les conseils généraux et les conseils de bourgeoisie, mais la désunion avec le milieu consulaire avaient conduit à un éloignement des juges auxquels on reprochait la trop grande ingérence. Mai 1562 fut l'occasion de leur retour. Le plus intéressant quant à l'engagement confessionnnel de la ville est que les magistrats présents lors de ces réunions avec les capitouls appartenaient tous au milieu le plus radical de la cour souveraine, c'est-à-dire les membres du syndicat de 1562 : Antoine de Paulo, secondé activement par Guérin d'Alzon, Vidal Ausone et l'avocat général Jean Deygna. En transcendant les conflits traditionnels toulousains, en provoquant une coopération entre instances jusque-là rivales, un groupe confessionnellement très engagé mit en œuvre une politique de

\footnotetext{
${ }^{19}$ Pierre Delpuech, seigneur des Maurices, capitoul en 1562 et mort avant 1584 ; La Popelinière, Histoire de La France..., op. cit., f $311 \mathrm{v}$.

${ }^{20}$ Dom Devic et Vaissète, Histoire générale de Languedoc, Toulouse, Privat, 1889, t. XI, p. 548

${ }^{21}$ François Delpuech, seigneur de La Croix-Falgarde, mort en 1604 : il fut capitoul en 1567 et trésorier de France de 1580 à 1593.

22 Pierre-Jean Souriac, Une société dans la guerre civile. Le Midi toulousain au temps des troubles de religion (1562-1596), Thèse de doctorat - Université de Paris IV-Sorbonne, 2003, vol. 1, p. 337.

${ }_{23}$ Arch. mun. Toulouse, BB 11 et BB 12 : délibérations des conseils de la ville de Toulouse. A l'automne 1567 et à l'automne 1568, lors du début de la seconde et troisième guerre civile, les conseils de ville élargis eurent lieu environ tous les deux ou trois jours, avec systématiquement un membre du Parlement comme assistant.
} 
radicalité catholique dont la force provint de la cohérence qu'il imposa aux décisions alors prises, et ce, dans une unanimité silencieuse des autres élites.

Conjointement à ce basculement politique, la ville se forgea un imaginaire militaroconfessionnel qui allait l'accompagner tout au long des guerres, voire jusqu'à la fin de l'Ancien Régime. Les hommes au pouvoir assimilèrent la sédition protestante à une prise de la ville provoquée par la trahison de ses élites. Une rhétorique de la cité soumise et souillée par l'hérétique entraîna alors un double sentiment de culpabilité : celui d'avoir failli face à la menace calviniste et celui d'une communauté responsable de ses malheurs en raison de la défection d'une partie de ses membres. Va alors se construire toute une mémoire citadine de la réconciliation et du pardon par l'utilisation d'outils symboliques valorisant la catholicité sans faille de la communauté régénérée après la semaine d'émeute. Un livre d'histoire fut commandé à un ecclésiastique toulousain pour mettre en mémoire les événements selon la trame narrative d'une libération ${ }^{24}$. Les deux cent pages qu'il écrivit alors composent une suite chronologique de dénigrements des mauvais citadins séduits par la nouvelle opinion, et une apologie de la réaction salvatrice menée par le milieu catholique inféodé au Parlement. A côté de ce récit hagiographique, des mesures répressives furent prises envers les capitouls destitués : leurs armes et leurs effigies furent arrachées des murs de la maison de ville et du livre consulaire, la sentence prononcée à leur encontre par le Parlement fut gravée sur une plaque de marbre et placée à la porte principale de l'hôte de ville, à côté de la tête desséchée du seul magistrat capturé et exécuté. Enfin, mobilisant la communauté urbaine, une procession expiatoire fut instituée sur ordre conjoint du Parlement et du consulat le 17 mai de chaque année, procession de demande de pardon pour cette défaillance citadine, procession d'action de grâce pour l'heureuse libération de la ville. Sur une lettre du clergé, le pape autorisa la procession et accorda les indulgences requises. Cependant, le roi chercha à interdire chacune de ces actions catholiques au nom de la réconciliation religieuse : destruction des livres de Bosquet, retrait de la tête du capitoul exécuté et abandon de la procession. L'ouvrage en question fut pourtant réédité et traduit en 1595, la façade de la maison de ville nettoyée seulement lors du passage du roi en février 1565 et quant à la procession, elle fut renouvelée chaque année jusqu'à la Révolution française, avec même une tentative de réintroduction en 1862. De manière affirmée, la communauté toulousaine créa sa mémoire d'une citadelle martyr mais catholique, dotée d'un militantisme intransigeant à la hauteur de ce que fut sa faute, et décidée à rappeler éternellement son engagement religieux.

\section{Intransigeance catholique et consensus urbain}

Dans l'engagement belliqueux, la communauté urbaine se souda autour d'une acceptation générale de la radicalité qui conduisit paradoxalement à une sorte de sérénité, une confiance dans l'exclusivisme confessionnel et les choix politico-religieux qu'il impliquait. La ligue débutée en 1589 à Toulouse ne fut pas une surprise, mais le conséquence logique d'une unité civique qui en avait intégré les ressorts idéologiques depuis plusieurs années.

Pour assurer ce consensus, la ville engagea un processus de purge sur une quinzaine d'années. Tout ceux que les magistrats au pouvoir jugeaient être de potentiels opposants à l'engagement catholique furent systématiquement désignés puis pourchassés au nom du devoir civique. La première entreprise d'épuration fut menée au lendemain même des émeutes de mai 1562 : du 25 mai au 17 décembre 1562, le Parlement de Toulouse promulgua 1690 décrets de prise de corps, ce qui, avec les doublons, revint à 1128 condamnations $^{25}$. Le motif officiel était

\footnotetext{
24 Georges Bosquet, Histoire de M.G. Bosquet sur les troubles advenus en la ville de Toulouse l'An 1562, Toulouse, R. Colomiez, 1595 [d'une traduction latine d'une édition de 1563].

${ }^{25}$ Joan Davies, "Persecution and protestantism", op. cit., p. 35 ; arch. mun. Toulouse, AA 14/1 : liste des personnes dont le Parlement de Toulouse a ordonné l'arrestation et fait saisir les biens du 25 mai au 17 décembre 1562.
} 
l'acte séditieux, et non la pratique réformée toujours autorisée selon l'Edit de Janvier ; cependant, nos magistrats catholiques prirent soin de cibler ceux qui de prêt ou de loin avaient été aperçus aux prêches réformés de la ville. Tous ne furent pas exécutés, loin de là, et si les têtes volèrent à en croire le très catholique Monluc, la plus grande partie des condamnés avait cependant trouvé refuge à Montauban ou à Castres. C'est là qu'ils attendirent l'édit de pacification du printemps 1563 pour tenter de timides retours en ville ${ }^{26}$. Les sept capitouls destitués en mai 1562 et encore survivants mirent plus de trois ans à revenir et plus de dix à récupérer leur dignité et leurs biens ; les autres bourgeois aussi bien que les conseillers du Parlement suspects d'hérésie et ayant préféré fuir lors des troubles furent dans une situation tout aussi délicate en subissant des brimades à chaque nouvelle alerte. Ces procédures de purges se renouvelèrent au début de tous les conflits, au moins jusqu'au milieu des années 1570:1567, 1568, 1572 et 1574 furent des années de confection de listes sur lesquelles les suspects toulousains étaient inventoriés, pour être ensuite confinés chez eux pour les femmes, emprisonnés pour les hommes, ou considérés comme fuitifs quand on ne les trouvait nulle part ${ }^{27}$. Cette politique de marginalisation de la minorité réformée conduisit à un véritable processus de disparition du milieu, soit par la lassitude des protestants convaincus qui préférèrent rester hors de la ville avec l'enracinement du conflit, soit par le retour dans le giron de l'Eglise des indécis et curieux du début de la décennie 1560. Sur ce dernier point, Thierry Wanegfellen a déjà bien montré le cheminement de ces croyants du XVI ${ }^{\mathrm{e}}$ siècle, attirés par la nouveauté des prêches réformés naissants et légalisés entre 1561 et 1562 sans pour autant rompre avec Rome, et qui, inquiets de la radicalisation liée aux conflits, revinrent dans le droit chemin de l'Eglise après 1562 en prétendant ne l'avoir jamais quittée $e^{28}$. Ainsi, ce mouvement de purge engagé par le Parlement eut, pour les catholiques toulousains, le mérite de faire disparaitre l'altérité confessionnelle, si bien que les listes de suspects disparurent des procédures municipales de sauvegarde religieuse au milieu des années 1570. A noter cependant qu'à partir de 1574, les ennemis n'étaient plus seulement les protestants, mais aussi les catholiques modérés qui, scandalisés par le massacre de la Saint-Barthélemy, cherchaient à promouvoir une voie médiane, une voie qualifiée de politique. En Languedoc, le gouverneur provincial, Henri de MontmorencyDamville se prétendant mal-content de la politique royale, fut leur chef de file, et ses proches furent l'objet de mesures répressives quand ils résidaient à Toulouse.

Parallèlement à ce processus de purge, se succédèrent des mouvements catholiques de mobilisation individuelle qui appelaient les fidèles à s'unir contre les huguenots par la prière et par les armes. Apparurent alors les premières formes de ligues catholiques dont le but n'était pas de créer une structure partisane autonome à l'image du parti protestant, mais d'encourager les consciences individuelles à défendre l'Eglise romaine dans le cadre de l'action monarchique. Ce mouvement toucha l'ensemble du royaume, dans une sorte de temps préparatoire avant la grande cassure des années $1590^{29}$. Le premier acte associatif catholique repéré à Toulouse remonte à mars 1563 : le 2 de ce mois, était signée au palais du Parlement une association jurée entre les principales autorités civiles, militaires et ecclésiastiques de Guyenne et Languedoc, s'engageant à défendre le roi et l'Eglise, les armes à la main s'il le fallait, contre les agressions avérées et répétées des protestants du pays ${ }^{30}$. Ce texte appelait explicitement à la prise d'armes contre les protestants,

\footnotetext{
${ }^{26}$ Blaise de Monluc, Commentaires, Paris, Gallimard, coll. "La Pléiade", 1964, p. 506 : Et des le lendemain commençarent à faire justice et ne vis jamais tant de testes voler que là.

${ }^{27}$ Joan Davies précédemment citée utilise ces listes pour tenter une approche sociologique des milieux réformés toulousains ; voir aussi Paul Romane-Musculus, "Les protestants de Toulouse en 1568", B.S.H.P.F., avril-juin 1961, p. 69-94 ; du même auteur, " Les protestants de Toulouse en 1574", B.S.H.P.F., octobre-décembre 1964, p. $272-283$.

${ }_{28}$ Thierry Wanegffelen, Ni Rome ni Genève. Des fidèles entre deux chaires en France au XVI siècle, Paris, Champion, 1997, p. 257.

${ }^{29}$ Joseph Leclerc, "Aux origines de la Ligue, premiers projets et premiers essais (1561-1570)", Etudes, avril-mai-juin 1936, 73e année, t. 227, p. 288-202 ; Jean-Marie Constant, La Ligue, Paris, Fayard, 1996, 514 p. ; Denis Crouzet, Les guerriers de Dieu. La violence au temps des troubles de religion. Vers 1525-vers 1610, Seyssel, Champ Vallon, coll. "Epoques", 1990, 2 t.

30 Arch. mun. Toulouse, AA 18, p. 110 ; voir aussi, Henri de La Popelinière, Histoire..., op. cit., f 315 r-v. Les principaux signataires de cette association étaient : le cardinal Georges d'Armagnac, archevêque de Toulouse, Laurent
} 
et ce, sans commandement militaire, en dehors de toute armée royale, au seul son du tocsin. C'était, à proprement parler, un appel à la mobilisation au nom de sa foi, un appel à la guerre civile. Cette première ligue toulousaine n'eut pas de suite puisque la paix d'Amboise contrecarra ses ambitions belliqueuses le même mois que sa signature. A contre-courant des espérances toulousaines nées durant la guerre, la couronne tenta une nouvelle fois l'expérience de la coexistence. Les élites municipales obtinrent en compensation que le culte réformé ne soit pas rétabli dans leur ville. Cet élan associatif fut revitalisé au début de la troisième guerre de Religion, à l'automne 1568, par un appel à la croisade : Hector d'Ossun, évêque du Couserans, chassé de son palais par les réformés, vint à Toulouse pour prêcher une guerre sainte contre les hérétiques. Il y reçut un accueil enthousiaste, et le 12 septembre, fut scellée dans la cathédrale Saint-Etienne de Toulouse une nouvelle association jurée appelant le fidèle à prendre les armes et à mourir dans le Christ au nom de sa foi et de l'Eglise ${ }^{31}$. Elan mystique que l'on rencontrait ailleurs dans le royaume à la même époque, il déboucha sur un nouveau spasme de mobilisation catholique dans la société urbaine ainsi que sur une petite armée qui se débanda rapidement une fois envoyée en opération. Enfin, les Toulousains reçurent avec le même enthousiasme la première Ligue du royaume, initiée par les Guise à l'été 1576, mais récupérée par le roi qui l'envoya à ses sujets pour la faire jurer. C'est ce que firent les Toulousains le 19 janvier $1577^{32}$. L'adhésion à ce nouveau mouvement associatif était toute aussi forte que lors des épisodes précédents, témoignant de l'élan catholique des élites comme du petit peuple malgré les quinze ans de guerre. Tous ces textes appelaient à la mobilisation individuelle contre l'hérétique, à la réactivité face à la moindre menace et à l'obligation morale de prendre les armes pour défendre le roi et l'Eglise. A partir de 1577, apparut même un effort durable d'organisation militaire par le biais d'une petite armée régionale placée sous les ordre du sénéchal de la ville. Ce type d'association militaire fut renouvelée à l'échelle de la province lorsque les conflits reprirent en 1586 et que s'appliquèrent dans le Midi les clauses du traité de Nemours ${ }^{33}$. Les ligueurs des années 1580 cherchèrent à lever une armée régionale quasi-permanente, ce qu'ils réussirent de 1586 à 1595. Le réflexe associatif s'était alors greffé sur le comportement catholique de mise en défense et accompagnait naturellement la prise d'armes.

A l'échelle des dirigeants de la cité, la prise de pouvoir opérée en mai 1562 par le milieu le plus intransigeant fut confirmée et défendue les années suivantes. Le milieu capitoulaire en poste suite à l'émeute conserva la haute main sur l'administration municipale, à l'exception du passage d'Henri de Montmorency-Damville dans la cité durant l'hiver 1569-1570. La proximité des armées protestantes imposa à la capitale du Languedoc l'accueil du gouverneur et de son armée, ce qui permit à ce dernier d'introduire une ou deux personnalités de ses amis à l'hôtel de ville,

de Strozzi, évêque d'Albi, Blaise de Monluc, lieutenant général du roi en Guyenne, Raymond de Fourquevaux, gouverneur de Narbonne et représentant de Guillaume de Joyeuse lieutenant général du Languedoc, Antoine de Lomagne baron de Terride et Louis de Carmaing comte de Nègrepelisse capitaines d'une compagnie d'ordonnance, les commissaires du Parlement et les capitouls.

${ }^{31}$ Joseph Leclerc, "Aux origines de la Ligue...", op. cit., p. 203 ; Devic et Vaissette, Histoire générale du Languedoc, op. cit., t. XI, p. 509, et pour le contenu de l'acte de la croisade : t. XII, col. 888 ; Denis Crouzet, Les guerriers de Dieu, op. cit., t.1, p. 386-389 ; Jean de Cardonne, Remonstrance aux catholiques de prendre les armes en l'armée de la Croisade instituée en la ville de Tholose contre les calvinistes huguenots, traîtres et rebelles, Toulouse, Colomies, 1568.

${ }^{32}$ J. Loutchitzky, Documents inédits pour servir à l'bistoire de la Ligue et de la Réforme, Sandoz et Fischbacher, 1873, p. 1929: édition d'une partie de l'acte d'association toulousaine et des délibérations municipales qui suivirent du 23 décembre 1576 au 20 mars 1577 pour l'établissement complet de l'association ; voir aussi pour le même acte : arch. mun. Toulouse, GG 828, feuille volante ; arch. mun. Toulouse, EE 15 : compte de Pierre Carrière, bourgeois de Toulouse commis trésorier au paiement des soldes de la cavalerie levée par Toulouse pour l'armée du sénéchal de Toulouse -1577 .

33 Arch. mun. Toulouse, BB 15, fo375 : délibérations des capitouls de Toulouse - 28 mai 1586 ; J. Loutchitzky, Documents inédits..., op. cit, p. 217-219. Le traité de Nemours est signé par le roi le 7 juillet 1585 : il consacre la victoire des catholiques intransigeants à la cour, par une abrogation de toutes les libertés religieuses concédées jusque-là, et par l'opposition à la montée sur le trône d'Henri de Navarre. Baptisé Edit de juillet par les Toulousains, il fut accueilli avec enthousiasme dès l'été 1585, et se concrétisa par un serment en août 1585 et une nouvelle association militaire en 1586. 
sans pour autant parvenir à le mettre complètement en tutelle ${ }^{34}$. Ce qui explique cependant que la ville ait eu à subir un deuxième coup de force catholique à la suite de la Saint-Barthélemy. L'annonce de la nouvelle du massacre parisien arriva à Toulouse par le biais de lettres royales le 31 août 1572, et le lendemain, les capitouls et les officiers du Parlement décidèrent d'enfermer dans les geôles de la Conciergerie du palais les protestants encore présents en ville et réunis pour un culte dans une bourgade voisine, Castanet. Ils s'opposaient alors aux appels de Pierre Delpuech qui réclamait leur massacre au nom du roi en enfermant cette poignée de calvinistes convaincus derrière des murs en théorie inviolables. Un mois plus tard cependant, le 4 octobre, un groupe composite de bourgeois, de conseillers au Parlement, d'avocats et d'artisans investit par surprise le palais et passa au fil de l'épée les réformés emprisonnés. C'est ainsi que mourut le célèbre jurisconsulte Jean de Coras, ainsi que les membres les plus en vue de la société réformée toulousaine ${ }^{35}$.

Denis Crouzet a réussi à individualiser dans ce petit groupe d'activistes le même milieu ultra-catholique que celui déjà rencontré précédemment, qu'il qualifie d'ailleurs de préligueur, placé dans une zone politique intermédiaire entre le Parlement et le capitoulat, auteur de ces massacres dans une relative impunité ${ }^{36}$. Parmi eux il a montré le rôle des deux frères Delpuech, de Pierre Madron, également capitoul au début des seconds troubles, de Pierre Belin beau-frère de Pierre Delpuech et capitoul en 1566, d'un fils de Jean Gestes capitoul en 1563, de Jean Brisault capitoul en 1568, de Sanson Lacroix, beau-frère du précédent et capitoul en 1568, de Jean Rogier, qui fut capitoul en 1563 et 1570, et enfin de Pierre d'Assézat, le contre-exemple du groupe, puisque son père comptait parmi les capitouls déchus de 1562. Au Parlement la famille de Paulo s'illustra encore comme relais essentiel de la faction ${ }^{37}$. Une nouvelle fois on mesure l'étroitesse des liens qui unissaient ce milieu radical, par les alliances matrimoniales, par l'occupation dans des périodes proches de la charge consulaire et probablement par une vie de foi commune. Sans que la preuve en ait été faite, ce petit groupe se comportait comme s'il s'était doté d'une structure confraternelle, dirigée autant contre le milieu protestant que contre le milieu modéré de la ville incarné par les proches de Montmorency-Damville ${ }^{38}$. Si les instances supérieures de la cour souveraine et du capitoulat semblent avoir été tenues à l'écart du coup de main catholique, une tendance plus radicale de la composante urbaine comptant des conseillers du Parlement et des bourgeois montra sa vitalité cette nuit du 4 octobre 1572. Et dans cette manifestation, ce n'était pas l'opposition Parlement/capitoulat qui était rejouée, mais une opposition de factions transcendant les clivages institutionnels. Le mécanisme fut ainsi le même qu'en 1562 et aboutit à un résultat similaire. Le coup de force anti-protestant mené au sein du Palais ne connut aucune suite judiciaire, au-delà de quelques condamnations morales, montrant par là même que la cour souveraine assumait ce dérapage et ne cherchait pas à en établir les responsabilités. Parallèlement, le milieu modéré qui avait repris pied en ville grâce à l'action du gouverneur de Languedoc fut définitivement écarté des instances décisionnelles et les élections capitoulaires des années suivantes portèrent au pouvoir d'authentiques catholiques engagés individuellement dans l'ensemble des actes associatifs et ligueurs. Si l'option modérée avait éventuellement pu être évoquée à l'aube des années 1570, comme l'option protestante l'avait été à l'aube des années 1560, la faction urbaine préligueuse sut à ces deux occasions reprendre le contrôle des affaires en usant à la fois de la violence et de ses réseaux politiques.

\footnotetext{
34 Arlette Jouanna, "Protection des fidèles et fidélité au roi : l'exemple de Henri Ier de Montmorency-Damville", in Yves Durand, Hommages à R. Mousnier, clientèles et fidélités en Europe à l'époque moderne, Paris, P.U.F., 1981, p. $279-296$.

35 Arch. mun. Toulouse, AA 44/34 et 34 ; Devic et Vaissète, Histoire générale de Languedoc, op. cit., t. XI, p. 495, 550 ; Janine Garrisson, Tocsin pour un massacre : la saison des Saint-Barthélemy, Paris, Centurion, 1968, p. 143.

${ }^{36}$ Denis Crouzet, Les guerriers de Dieu..., op. cit., t. II, p. 116.

37 Travaillent en même temps au Parlement Antoine de Paulo et son fils, Jean, encore simple conseiller, et marié à la sœur de Pierre et François Delpuech.

${ }^{38}$ Ibid, p. 118. Jean-Etienne Duranti, alors procureur général du Parlement dans les années 1570, semble avoir initié la création de plusieurs confréries sur Toulouse, celle du Saint Esprit, de la Miséricorde et des Pénitents.
} 
Aussi violente qu'ait été la réaction de 1572, elle n'atteint pas le paroxysme de 1562, et fut suivie d'un calme qui ne fut troublé que brièvement lors de l'hiver 1589. A partir du milieu de la décennie 1570, se mit en place dans Toulouse, du moins au niveau des instances dirigeantes, un consensus fondé sur l'intransigeance religieuse, et ainsi, sur un engagement partisan qu'il n'était plus question de remettre en cause. Les actes ligueurs furent signés sans hésitation, dans une volonté affichée de témoigner de l'unanimité urbaine. Cette unanimité se retrouve également dans l'apaisement des conflits au sein même de la ville : fin des purges, fin des querelles incessantes de procédure entre capitoulat et Parlement, et même, un relatif désengagement de la cour souveraine dans la mise en tutelle de la municipalité. Le moteur de ce consensus fut la mise en défense citadine dès lors ininterrompue et encadrée de manière de plus en plus rationnelle. La création d'une garde urbaine professionnelle, une rotation régulière dans la mobilisation des bourgeois, la régularité des impôts extraordinaires servant à financer la protection armée permirent de pérenniser un état de guerre permanent mais assumé. La vision que la ville avait d'elle-même, une citadelle catholique assiégée, ne se traduisait plus dans des spasmes de violence intenses et limités, mais au contraire dans une normalisation du rapport au militaire. Le milieu catholique qui s'est saisi du pouvoir au fil des guerres réussit à imposer à la cité son modèle d'engagement confessionnel et partisan, la rassurant sur son devenir et son salut. Il fut secondé en cela par un chef de guerre qui sut parfaitement se fondre dans le paysage urbain.

François de La Valette-Cornusson, petit seigneur originaire du Rouergue, fut investi de la charge de sénéchal en 1574, puis de commandant militaire sur la sénéchaussée de Toulouse en $1575^{39}$. Il exerça cette mission jusqu'à sa mort en 1586, date à laquelle il fut remplacé par son fils. Ce capitaine était un proche de la famille des Joyeuse, dont le chef était lieutenant général en Languedoc et un fils, principal favori d'Henri III. De plus, il était cousin germain de Jean-Louis de Nogaret de La Valette, duc d'Epernon, autre proche du roi. Tout concourrait pour faire de cet hobereau méridional un homme de pouvoir, un exemple de cette noblesse seconde, intermédiaire entre le souverain et son territoire, un homme politiquement en devenir ${ }^{40}$. A ce titre, il lui était demandé d'assurer une bonne entente entre représentants du souverain et corps politiques régionaux, ce qu'il réussit remarquablement à Toulouse. Alors que la ville savait se montrer rétive à tout gouverneur dont elle était en théorie exemptée par ses privilèges, elles accueillit Cornusson sans résistance et finança pendant dix ans ses campagnes antiprotestantes. Ce dernier accepta en retour de prendre sous son aile les mouvements associatifs du milieu catholique et ainsi favorisa la préparation de la Ligue. Lui-même proche de la mouvance ultra-catholique, il fut l'allié de taille du milieu au pouvoir dans Toulouse et offrit un prolongement militaire très concret pour leurs aspirations à la guerre civile. Par ailleurs, il incarnait la caution royale, et légitimait par sa participation la radicalité confessionnelle de la capitale languedocienne. L'intransigeance catholique apparaissait dès lors pour les citadins toulousains comme une expression de l'obéissance au roi et un programme politique défendu par l'ensemble des autorités présentes en ville.

\section{La Ligue : entre triomphe et essoufflement de l'intransigeance armée}

La ville était ainsi acquise à la radicalité catholique, candidate potentielle à des expériences politiques qui n'avaient pourtant jamais été envisagées jusque-là. La question qui fut posée alors aux Toulousains dissocia pour la première fois des guerres de Religion la fidélité au roi de la fidélité à sa foi. Que faire face à un roi qui ne suivait plus les conseils du plus catholique de ses

\footnotetext{
${ }^{39}$ Arch. mun. Toulouse, AA 18/347, p. 352 : lettre du roi adressée à Cornusson - 9 janvier 1575.

40 Laurent Bourquin, Noblesse seconde et pouvoir en Champagne aux XVI et XVII siècles, Paris, Publications de la Sorbonne, 1994.
} 
gentilshommes ? Que faire face à un roi qui était lui-même le fruit du démon, hérétique relaps venu à la couronne par le hasard des règles successorales?

La défiance à l'égard d'Henri III fut plus tardive à Toulouse qu'à Paris. La journée des barricades parisiennes et l'exil forcé du roi hors de sa capitale suite aux pressions de la rue derrière le duc de Guise ne firent pas l'objet à Toulouse d'informations particulières. En revanche, comme l'a montré le texte du clergé toulousain en janvier 1589, l'assassinat de Blois ralluma des tensions au sein de la ville ${ }^{41}$. Le 7 janvier 1589, la nouvelle était connue de l'ensemble des milieux décisionnels municipaux qui firent alors le choix de favoriser la désobéissance. Très symboliquement, le premier acte ligueur posé par les Toulousains concerna l'accueil ou le renvoi des députés qui avaient assisté aux Etats généraux de Blois. Le jour même de la requête du clergé, s'annonça aux portes de la ville son sénéchal, Jean de Cornusson, fils du précédent, qui avait été député de la noblesse de la sénéchaussée aux funestes Etats. Il prétendait disposer d'ordres royaux quant à la conservation de la cité et exigeait donc au nom du roi d'être accueilli selon son rang. Les portes lui furent fermées, et il fut prié de s'éloigner. La ville refusait l'entrée à l'envoyé du roi, premier acte de désobéissance. Parallèlement, elle laissait pénétrer dans son enceinte un autre député revenant de Blois, Urbain de Saint-Gelais, évêque de Comminges, accompagné d'un avocat au Parlement connu pour ses affinités avec le milieu Guisard, un certain Etienne Tournier $^{42}$. Ce sont probablement eux qui portaient dans leurs bagages une lettre du conseil parisien enjoignant aux Toulousains de rejoindre la Sainte Union protégée dès lors par le frère du défunt duc, Charles de Lorraine duc de Mayenne. Ainsi, la question religieuse qui avait fini par créer un consensus urbain autour de l'intransigeance, et ce, dans une relative bonne conscience de fidélité monarchique, se voyait investie d'un prolongement politique inédit. Que faire puisque le roi avait trahi ? De manière significative au regard des décennies précédentes, c'est collectivement que fut élaborée une solution originale à cette crise.

Acteur majeur de la mobilisation utltra-catholique depuis 1562, le peuple toulousain exigea un droit de participation aux discussions sur la position que devait adopter les élites. Le cœur politique de l'identité urbaine fut alors véritablement incarnée par la maison de ville, lieu du pouvoir municipal, lieu de tous les débats : vers elle, convergèrent des citadins de plus en plus nombreux, de plus en plus excités par la situation et de plus en plus décidés à choisir la défense de sa foi plutôt que la cause royale. Ils réclamaient avec force la tenue d'un conseil général extraordinaire en prétendant recréer une sorte d'assemblée de l'université de la ville, forme institutionnelle abandonnée depuis le XIII ${ }^{\mathrm{e}}$ siècle mais encore ancrée dans les mémoires toulousaines. Le 8 janvier 1589, un conseil général comptait déjà au moins 100 personnes non prévues selon le greffier du consistoire ; le 23 janvier, 500 Toulousains s'étaient présentés devant la salle du conseil ; le 26 janvier enfin, entre 500 et 600 citadins réclamaient le droit d'opiner comme tout membre du conseil général ${ }^{43}$. En juillet 1589 encore, un texte signé du provincial des minimes appelait de ses vœux un conseil libre et non restreint, seule légitimation envisageable aux décisions des magistrats. Limité à 40 bourgeois, le conseil général se voyait ici chahuté par une fraction urbaine exprimant la nécessaire collégialité qu'imposaient les alternatives offertes à la crise : d'une certaine manière, elle cherchait à préserver le consensus municipal qui semblait menacé depuis le coup royal contre le duc de Guise. Les autorités en place, notamment le premier

\footnotetext{
${ }^{41}$ Arch. mun. Toulouse, BB 16, $\mathrm{f}^{\circ} 91 \mathrm{r}$ : le 7 juin 1588, le conseil de ville reçut une lettre du roi assurant la ville de son soutien dans sa conservation ; Mark Greengrass, "The Sainte Union and the provinces : the case of Toulouse", The Sixteenth century journal, vol. XIV, $\mathrm{n}^{\circ}$ 4, 1983, p. 469-496. Voir une partie de l'édition des délibérations municipales pour 1589 dans : J. Loutchitzky, Documents inédits ..., op. cit., p. 242-255.

${ }^{42}$ Urbain de Lansac de Saint-Gelais : conseiller au Parlement de Toulouse, évêque du diocèse de Comminges, actif dans la défense de son diocèse contre les protestants dès le début des années 1580. Délégué aux Etats Généraux de Blois en 1588, il participa activement à la ligue toulousaine en 1589, devenant le gouverneur de la ville. Suite à un différend avec Guillaume de Joyeuse, il dut quitter Toulouse et continua ses menées ligueuses depuis son diocèse en entretenant des rapports diplomatiques avec l'Espagne.

${ }^{43}$ Arch. mun. Toulouse, BB 16, $\mathrm{f}^{\circ} 231 \mathrm{r}, \mathrm{f}^{\circ} 244 \mathrm{r}-\mathrm{v}, \mathrm{f}^{\circ} 249 \mathrm{v}$ : délibérations des capitouls et du conseil général - 8, 23 et 26 janvier 1589.
} 
président du Parlement de Toulouse, considéraient cette revendication comme un desordre, dans lequel tous voulloyent oppiner tumultueusement, estant plustost une confusion que acte digne de conseilh de ville ${ }^{44}$. Les capitouls se disaient dépassés, mais de fait, laissèrent faire la rue, permettant sur autorisation du Parlement d'augmenter le nombre de participants au conseil à 80 personnes. Les citadins se montraient alors particulièrement agressifs, faisant craindre aux magistrats municipaux une dégradation en émeute, même si celle-ci ne vint jamais ${ }^{45}$. Il est d'ailleurs difficile d'identifier les cibles de cette violence décrite par les capitouls, la ville ne semblant pas divisée en deux factions distinctes, mais choquée par les récents événements de la cour. La soudaineté de la demande ainsi que sa dissipation rapide au bout d'un mois indiquent qu'il ne s'agissait nullement d'une sorte de révolution urbaine, au contraire. Le pouvoir capitoulaire se voyait ici confirmé comme chef d'orchestre de la position politico-religieuse municipale. C'est l'importance du débat qui engendra cette pression de la rue, et le besoin d'une décision collective d'où sortirait renforcée l'unité citadine. Et sur cette pression, c'est l'intransigeance catholique qui fut choisie, renouvelant ainsi le consensus urbain autour de la radicalité religieuse.

Dans un élan similaire à celui du petit peuple, les élites eurent besoin elles aussi de se doter d'une instance collégiale légitimant leurs décisions aux yeux de tous. Ainsi fut créé un nouveau conseil destiné à la gestion des affaires politiques et militaires de la ville : un bureau des Dix huit six ecclésiastiques, six bourgeois dont deux capitouls, six officiers du Parlement. Il fut proposé par le vicaire général le 7 janvier et accepté par le Parlement sur proposition des capitouls le $8^{46}$. Naturellement, on pourrait y voir une expérience toulousaine du Conseil des Seize parisien qui se substitua au pouvoir municipal au temps de la Ligue. Il n'en fut rien. Ce bureau toulousain n'eut qu'une activité limitée sur les décisions municipales. S'il donna quelques avis aux capitouls, ils ne furent que peu nombreux, et la politique urbaine continua d'être le fait du corps de ville traditionnel, très investi notamment dans la mise en défense de la cité. La fonction de ce bureau des Dix huit était ailleurs : il incarna une forme d'achèvement du processus politique de concorde décisionnelle à l'échelle de la cité. Les trois pouvoirs toulousains y étaient représentés et décidés à se concerter pour prendre en main les destinées municipales. Les capitouls n'étaient pas des ennemis à mettre en tutelle, mais les meneurs d'une politique dont le bureau des Dix Huit était la caution collégiale. Comme pour les assemblées générales élargies, cette instance nouvelle ne fut en rien révolutionnaire, mais fut une expression supplémentaire du consensus urbain en faveur de l'intransigeance religieuse. Elle ne résista pas d'ailleurs à l'érosion du temps, lorsque les questionnements de janvier 1589 furent tranchés et considérés comme acquis. Il disparut sans cérémonie au printemps 1589.

Malgré cette entente manifestée au sein des élites et de la rue, la ville ne put échapper aux épisodes de violence, corollaire indissociable du choix ultra-catholique. Elle se choisit d'abord un champion en la personne de l'évêque de Comminges, Urbain de Saint-Gelais. Ce dernier, déjà connu pour son catholicisme radical, était resté à Toulouse après son retour des Etats Généraux de Blois. Proche des officiers du Parlement liés à la famille des Guise, il obtint de la cour souveraine la charge de gouverneur de la ville le 29 janvier 1589, en raison de l'urgente nécessité des affaires qui se presentent, levée d'armes par toute ceste ville de Tholose et l'absence de Monsieur de Joyeuse, lieutenant et gouverneur en Languedoc ${ }^{47}$. Sa mission consistait à maintenir l'ordre en ville, ce qui était la mission habituelle confiée au titulaire de cette lieutenance. Cependant, le choix d'un ligueur connu sur la place publique dissimulait mal le caractère militant donné à la fonction, avec l'espoir de voir rétablir l'ordre par l'orientation des violences urbaines derrière la cause ultra-catholique.

\footnotetext{
44 Arch. mun. Toulouse, BB 16, f०244r-v : délibérations du conseil général - 23 janvier 1589.

45 Ibid., f $\mathrm{f}^{\circ}$ 240r : délibération du conseil général - 21 janvier 1589 : En raison de la nouvelle des meurtres et massacres inhumains commis es personnes de messieurs les cardinal et duc de Guyse, le peuple est si fort esmeu et irrité que a peyne le peult on fere contenir, c'estant eslevé en armes par telle furie qu'il est a craindre qu'en fin il n'y ayt ung tres grand desordre quy pourroict causer la ruyne et perte d'icelle et par la donner moyen aux hereticques noz. ennemys d'entreprendre sur nous.

46 Ibid., fo 234r : délibération du capitoulat - 8 janvier 1589.

47 Arch. mun. Toulouse, EE 19/feuille volante : nomination d'Urbain de Saint-Gelais par le Parlement de Toulouse 29 janvier 1589.
} 
Revendications de la rue et positionnement des élites convergeaient vers un radicalisme sensiblement identique pour lequel le choix du gouverneur devait servir de catalyseur afin de pacifier les esprits. Cet acte ne suffit pas cependant, et c'est une nouvelle fois dans le sang que les Toulousains trouvèrent une solution aux tensions devenues insupportables.

Le premier président du Parlement, Jean-Etienne Duranti, soucieux de la tournure que prenaient les événements, fit les frais de ce besoin de violence ${ }^{48}$. Hostile à la pression de la rue sur le pouvoir consulaire, résolument opposé à une rupture avec Henri III, il incarnait encore la fidélité monarchique alors qu'il avait été un des principaux agitateurs catholiques de la cour, notamment lors massacres de 1572, lorsqu'il en était procureur général. Critiqué pour la richesse de son train de vie, conspué et marginalisé, il subit plusieurs tentatives d'agression au cours du mois de janvier, et finit par demander la protection des capitouls et de l'évêque de Comminges au début de février alors qu'il risquait d'être lynché en pleine rue. Enfermé dans un des couvents de la ville, celui des Jacobins, il ne put échapper à la vindicte populaire qui vint l'y chercher pour l'assassiner. On arracha la barbe à son cadavre, on le traina dans les rues de la ville attaché à la queue d'un cheval, et on l'exposa plusieurs jours durant place du Salin, sur le gibet municipal, drapé dans le portrait d'Henri III arraché des murs du Parlement. Son gendre, alors avocat général à la cour, subit sensiblement le même sort. Ce 10 février 1589, l'action violente de la rue venait de trancher le débat qui opposait depuis un mois fidélité au roi et fidélité à sa foi. Paradoxalement, c'est un des membres du milieu ultra-catholique ayant hésité dans cet ultime choix politico-religieux qui paya au prix fort l'engagement citadin dans l'ultime étape de l'intransigeance ${ }^{49}$. Cet acte peut être interprété comme le triomphe du cheminement confessionnel de la ville depuis 1562, comme la manifestation d'une collectivité urbaine ayant préféré perdre son roi plutôt que de trahir ses convictions religieuses. L'absence de poursuite à l'encontre des assassins, le laisser-faire de Saint-Gelais, des capitouls et du reste du Parlement indiquent sinon une complicité, du moins une satisfaction de la part des élites d'avoir laissé régler cette question par la violence de la rue. Jusqu'à la pacification de 1596, personne dans Toulouse ne chercha trop à évoquer Duranti et son gendre Daffis, les événements étant jugés déplorables, mais sans autre conséquence. En revanche, peu de jours après, les Toulousains firent donner un service solennel dans la cathédrale en l'honneur du duc de Guise et de son frère, dans une messe célébrée par l'évêque de Comminges et une oraison funèbre prononcée par le principal des Minimes $^{50}$. Pour soulager leur conscience, ils envoyèrent une lettre à Sixte Quint dès le mois de février 1589 afin de lui demander son approbation, ce qu'il accorda mais de manière ambiguë, la désobéissance à Henri III et l'assassinat de son principal représentant n'étant pas du goût du souverain pontife.

Une nouvelle fois, l'exploration du milieu au pouvoir dans la ville fait état des mêmes réseaux, des mêmes personnes ou de leurs descendants. On retrouve toujours la famille de Paulo,

\footnotetext{
${ }^{48}$ Devic et Vaissète, Histoire générale du Languedoc..., op. cit., t. XI, 774.

49 Jean-Etienne Duranti (1534-1589) : il fut d'abord procureur général au Parlement de Toulouse avant d'être reçu premier président en 1581. Il participa activement à la défense du catholicisme toulousain : on lui prête une complicité dans les massacres d'octobre 1572 à la Conciergerie du Parlement ; on lui connait aussi une œuvre de protection pour les œuvres dévotes. Il fut à l'origine des confréries du Saint-Esprit, de la Miséricorde et des Pénitents de Toulouse, confréries qui rassemblèrent les élites catholiques de la cité. C'est à sa demande que les Jésuites vinrent s'installer à Toulouse en 1566, et que les ordres religieux chassés des villes protestantes furent accueillis au fil des guerres. Il écrivit un ouvrage sur les rites catholiques : Rits de l'Eglise, édité à Rome en 1590 (posthume). Une abondante bibliographie évoque ce personnage, devenu a posteriori un des grands hommes de Toulouse, et dont la statue trône à ce jour dans le hall d'entrée du palais de justice.

${ }^{50}$ Devic et Vaissète, Histoire générale du Languedoc..., op. cit., t. XI, p. 779. Le Principal des Minimes, ou son provincial selon les versions, se nommait Richard et figure dans l'ensemble des manifestations ligueuses de Toulouse : aux côtés de Saint-Gelais, il fit partie des prêcheurs qui appelèrent la rue à prendre les armes dans les mois difficiles de janvier et octobre 1589, appela la tenue de conseils généraux élargis à tout le peuple, et prononça des oraisons funèbres pour les ligueurs morts dans leur mission, les Guise et Jacques Clément notamment.
} 
avec un membre au capitoulat et un autre à la cour souveraine ${ }^{51}$. Les Assézat, les Lardat, les Delpuech, toujours entre Parlement et corps de ville, occupaient en outre des fonctions financières au Bureau des Finances de la ville, organe fiscal qui servit à financer une partie des opérations ligueuses. Rien ne changea en février 1589 lors du basculement de Toulouse vers la Ligue, tous les ressorts inventés jusque-là pour mettre la ville en défense et s'impliquer dans les guerres civiles régionales furent confirmés sans que ni le personnel ni les attributions ne soient remplacées. Les années 1570 et 1580 avaient mis en place un système qui fut investi par l'administration ligueuse, parce que c'est l'ensemble des institutions toulousaines, dans un consensus général qui adhéra à la Sainte Union. Sans connaître le contexte historique, un lecteur des archives toulousaines des décennies 1580 et 1590 aurait bien du mal à repérer des mutations administratives et sociologiques. Même si à partir du 10 février 1589 Toulouse ne reconnut plus Henri III comme son souverain légitime, les hommes en place restèrent à leur poste et assumèrent dans la révolte ce qu'ils avaient toujours fait dans la légalité. L'exemple de Duranti atténua probablement les ardeurs des plus défiants, mais jusqu'à la cérémonie religieuse organisée en faveur du premier président en 1591, il n'y eut aucune voix discordante. Le meilleur exemple de ce consensus mi-choisi, mi-imposé fut la résistance de la collégialité du Parlement : malgré le coup de force mené contre son premier président, seuls deux conseillers acceptèrent de quitter la ville vers le nouveau siège de justice que Henri III venait d'ériger à Carcassonne ${ }^{52}$. Dans cette affaire, l'unité et la cohésion du milieu parlementaire l'emportèrent sur la considération légaliste et sur l'opposition entre radicaux et modérés qui ne pouvait pas ne pas exister ${ }^{53}$.

Une fois la désobéissance adoptée, se posait la question des alliés. Toulouse chercha d'abord à rassembler autour de cette option l'ensemble de son plat pays : on vit alors les magistrats du Parlement les plus engagés quitter la capitale provinciale pour aller prêcher la Sainte Union auprès des villes et villages environnants, véritables missionnaires de la Ligue ${ }^{54}$. De même, elle délégua des envoyés à Paris, mais davantage pour tenir la capitale informée de la situation que pour prendre ses instructions sur la marche à suivre ${ }^{55}$. Cependant, ils furent doublés par l'organisation languedocienne inspirée directement par le mouvement parisien alors que les Toulousains s'étaient montrés nettement plus indépendants. L'homme fort de la Ligue languedocienne fut Guillaume de Joyeuse, maréchal de France. Il était secondé par son fils Antoine-Scipion, Grand Prieur de l'Ordre de Malte à Toulouse et chef de guerre reconnu, ainsi que par son second fils, François, cardinal et archevêque de Toulouse de 1584 à $1600^{56}$. Ils se prononcèrent pour la Ligue au début du printemps, après quelques hésitations, et jurèrent le serment ligueur en même temps qu'une partie des délégués des Etats Provinciaux de Languedoc

\footnotetext{
51 Jean II de Paulo : fils d'Antoine de Paulo, président et principal acteur du syndicat catholique du Parlement de Toulouse durant l'émeute de 1562 ; Jean II fut reçu conseiller au Parlement de Toulouse le 30 janvier 1574, puis président en 1588. Il épousa Gaillarde Delpuech, fils de Pierre Delpuech, ardent catholique évoqué précédemment. Il mourut en 1621.

${ }^{52}$ M. Bénech, "La cour du Parlement de Toulouse séant à Castelsarrasin, épisode des troubles de la Ligue", Mémoires de l'Académie des Sciences, Inscriptions et Belles-Lettres de Toulouse, 4e série, t. IV, 1854, p. 28-29. En novembre 1589, un Parlement royaliste siégea dans la ville de Carcassonne selon l'édit de translation d'Henri III du 15 juin 1589 . Il y resta jusqu'à la prise de la place par les Ligueurs à la fin de l'année 1589 ; le roi tenta alors de le rétablir à Montpellier, mais faute de personnels, ce ne fut que le 6 avril 1593, qu'il siégea de nouveau, mais à Béziers.

${ }^{53}$ Carole Delprat, "Les magistrats du parlement de Toulouse durant la Ligue", Annales du Midi, t. 108, n 213, janviermars 1996, p. 39-62.

54 Pierre de Hautpoul seigneur d'Aussillon alla auprès des Etats de Comminges, les conseillers Ouvrier et Mansencal à Muret, Ciron et Bertier vers Joyeuse, Vézian et Bertier aux Etats de Languedoc avec François Delpuech sieur de La Croix Falgarde trésorier général de France, Le Conte en Agenais, Richard à Lavaur, Filère et Sénaux en Rouergue, Marion et Gay à Villefranche-de-Lauragais [arch. mun. Toulouse, CC 1990 : compte des affaires extraordinaires de la ville pour l'année 1589].

55 Délégation à Paris de l'évêque de Castres (Jean de Fossé) et d'un chanoine de la cathédrale pour le clergé, de M. Grégoire, bourgeois de la ville, et de Vignalz et Caumelz conseillers au Parlement [arch. mun. Toulouse, CC 1990, $\left.\mathrm{f}^{\circ} 8 \mathrm{r}\right]$.

${ }^{56}$ Pierre de Vaissière, Messieurs de Joyeuse (1560-1615), Paris, Albin Michel, 1926.
} 
le 20 avril 1589 à Castelnaudary ${ }^{57}$. Mayenne fit de Guillaume son gouverneur, et Antoine-Scipion son lieutenant général ${ }^{58}$. Le clan Joyeuse originaire du Languedoc et détenteur de la charge de lieutenant général de la province depuis près de 30 ans avait espéré une promotion au titre de gouverneur suite aux accidents de parcours de son titulaire, Henri de Montmorency, rallié aux Malcontents. Catholiques fervents, les hommes du clan se sentirent trahi par leur souverain quand celui rappela le duc à son service après sa réconciliation avec Henri de Navarre au début de l'année 1589. Ils passèrent alors collectivement dans le clan ligueur. Logiquement, Guillaume de Joyeuse vint alors dans sa capitale provinciale qui avait fait le même choix que lui, mais les choses lui apparurent alors plus complexes qu'elles ne le semblaient.

En effet, le 30 septembre 1589, le maréchal vint au Parlement pour faire enregistrer une trêve conclue avec Montmorency et s'opposa à l'installation d'une confrérie du Saint Sacrement dans la ville malgré les propositions des présidents de la cour. Galvanisé par un prêche du provincial des minimes, mobilisé dans une procession menée par l'évêque de Comminges revêtu de sa cuirasse, le peuple toulousain se mit en marche vers l'archevêché où logeait Joyeuse en grondant son mécontentement face aux décisions du maréchal. Les meneurs les plus charismatiques de la Ligue toulousaine s'en prenaient alors au chef provincial, jugé trop modéré et prêt à trahir cette sainte cause. Devant le tumulte de la rue, Joyeuse préféra s'échapper plutôt que risquer la confrontation. Il revint peu de jours après avec son armée et mit le siège devant Toulouse après avoir réuni les Etats provinciaux à Lavaur pour ouvrir une négociation. La manœuvre aboutit à un accord le 27 novembre 1589 prévoyant le renvoi de Saint-Gelais et la reconnaissance par les Toulousains de son autorité ${ }^{\prime 5}$. Les fidèles de l'évêque de Comminges tentèrent un ultime de coup de force en cherchant à s'emparer du Parlement peu de jours après, mais ils furent rejetés sur l'île de Tounis, puis vaincus par les forces conjointes du palais et de la maison consulaire. Ces événements sont surprenants parce qu'ils montrent que le principal adversaire militaire qu'eut Toulouse au temps de la Ligue provint des propres rangs catholiques. On ne sait pas en détail quelle fut la nature du différend entre le milieu toulousain au pouvoir et Guillaume de Joyeuse lorsqu'il vint au Parlement en septembre 1589. Cependant l'hostilité fut manifeste, et la radicalité toulousaine plus exigeante que les propositions du gouverneur provincial. La même mécanique que celle de 1562, 1572 et 1589 fut à nouveau enclenchée : mobilisation de la rue par des orateurs enflammés, cohésion des élites dans la direction de la lutte, et effort de guerre d'une capitale militaire. Mais en novembre 1589, les tenants de l'intransigeance durent céder, et finir par renoncer à l'audace de leur coup de force.

Toulouse resta dans le mouvement ligueur, mais sous contrôle languedocien par l'entremise de la famille de Joyeuse et des Etats Provinciaux. Il semble que le milieu qui avait pris le pouvoir en 1589, le même que celui qui avait conduit la ville sur les chemins de l'intransigeance depuis 1562, ait eu d'autres ambitions pour leur ville que celles des chefs languedociens. A l'image du rituel inventé à Toulouse autour de Jacques Clément, assassin d'Henri III mort sur les lieux de son crime, les Toulousains plaçaient dans la violence religieuse un absolu peu compatible avec les contraintes de la guerre ${ }^{60}$. A l'annonce de la mort du roi et de son assassin, un service funèbre fut célébré dans l'église des Dominicains en faveur de Jacques Clément, avec une oraison funèbre confiée au provincial des Minimes qui le plaça au rang des martyrs. Son portrait fut imprimé et placardé en ville pour édifier le peuple, et son nom fut intégré dans une litanie des saints très particulière à la cité. Le Parlement d'ailleurs ordonnait une procession annuelle au $1^{\text {er }}$ août de chaque année, pour se remémorer le régicide et rendre grâce à Dieu de cette libération. On retrouvait le même vocabulaire que celui mobilisé après les émeutes de 1562, mais il n'eut pas la

\footnotetext{
${ }^{57}$ Jusque là, le choix de Guillaume de Joyeuse n'avait pas paru si évident, puisque le roi lui adressait un mémoire et une lettre le 23 février 1589 lui rappelant son devoir de fidélité, le laissant nommer son second et lui accordant l'ensemble des deniers royaux de la province pour rétablir la situation que les événements toulousains avaient dégradée [Bibl. nat. France, Fr. 3420, f 74 r]

58 Devic et Vaissette, Histoire générale de Languedoc..., op. cit., t. XI, p. 785.

${ }^{59}$ Ibid., t. XI, p. 792-798; acte du traité entre Toulouse et Joyeuse : t. XII, nº 428.

${ }^{60}$ Ibid., t. XI, p. 789.
} 
même longévité. Evêque de Comminges, provincial des Minimes, officiers du Parlement cherchant à créer une compagnie du Saint Sacrement, tous ces hommes fondaient leur engagement civique sur des préoccupations catholiques plus radicales que les exigences pragmatiques des instances provinciales. Si jusque-là cette radicalité avait réussi à se prolonger politiquement par une occupation des postes décisionnels municipaux, à l'automne 1589, elle ne put subsister en raison d'enjeux partisans qui dépassaient la seule ville de Toulouse. La fièvre ultra-catholique de certaines élites municipales ne suffit pas à maintenir la ville sur ce chemin de la sanctification.

Dès lors, la capitale languedocienne traversa la Ligue sans se distinguer des autres composantes méridionales de l'intransigeance religieuse. La guerre était à ses portes, et elle honora sa mission de citadelle catholique en armant quelques troupes, en prêtant son artillerie et en entretenant ses fortifications ou sa garde. Il n'y eut plus de spasme urbain comparable à ce qui s'était passé en 1589 et c'est dans une relative atonie que Toulouse vécut ces années ligueuses. On assiste surtout à la fissuration du consensus construit patiemment depuis 30 ans. D'un point de vue symbolique d'abord, un service solennel fut rendu en l'honneur de Duranti le 5 décembre 1591 dans la cathédrale : l'ensemble des ordres de la ville y étaient représentés, témoignant d'un sentiment de culpabilité et d'un regain de vitalité des milieux plus modérés. Au niveau militaire, les capitouls finirent par s'engager sur les voies de la pacification en intégrant les mouvements de trêves de labourage qui se négociaient entre catholiques et protestants déjà depuis $1588^{61}$. A partir du printemps 1592, la municipalité envoya des députés aux négociations tenues avec les réformés de L'Isle-Jourdain, pour organiser, malgré la guerre, un minimum de sécurisation des campagnes et des routes. Il s'agissait d'éviter l'asphyxie complète du pays par un conflit qui devenait interminable. Une des conséquences de ce ralliement aux négociations de trêve fut l'acceptation du dialogue avec l'ennemi protestant. Dès lors, au-delà de l'hérétique, il fallait concevoir le réformé comme un membre du parti adverse, négocier avec lui comme avec un homme de guerre et non un barbare, ce qui conduisait à une première forme de sécularisation des conflits où les contraintes de la survie locale l'emportaient sur les principes religieux radicaux.

Dans un tel contexte, les chefs de guerre provinciaux secondés par les Etats et les principales villes du pays entamèrent un processus de négociation avec Henri IV à partir de février $1594^{62}$. Dans ces négociations qui mêlaient tous les ordres de la ville, fut négociée un apaisement des conflits et une reconnaissance du roi : la conversion de ce dernier avait grandement aidé à l'ouverture de ce dialogue, réduisant au silence une position de principe des Toulousains. Les choses allèrent ainsi vers la paix, jusqu'à un ultime coup de force ultracatholique. Le fils de Guillaume de Joyeuse, un ancien capucin connu sous le nom de frère Ange, mais revenu à la vie civile pour prolonger l'œuvre militaire de ses défunts père et frère en 1592, décida de rompre un accord qu'il trouvait peu satisfaisant pour sa personne ${ }^{63}$. Il pénétra alors avec ses hommes dans Toulouse le 11 avril 1595, alla directement au Parlement et fit ordonner à ce dernier l'arrêt des pourparlers. Il autorisa alors les conseillers qui lui étaient hostiles à quitter la ville, ce que firent 41 d'entre eux, alors que seulement 12 restèrent dans leur capitale. Il s'agissait selon Caroles Delprat des conseillers les plus jeunes et les plus enflammés, alors que la vieille

\footnotetext{
${ }^{61}$ Pierre-Jean Souriac, "Eloigner le soldat du civil en temps de guerre. Les expériences de trêve en Midi toulousain dans les dernières années des guerres de Religion", Revue historique, 306/4, décembre 2004, p. 788-818.

${ }^{62}$ Le principal commissaire royal fut Aymeric de Vic, entré dans Toulouse le 18 décembre 1594 ; en face de lui, se trouvaient huit bourgeois toulousains, deux présidents, quatre conseillers et l'avocat général du Parlement de Toulouse, l'évêque de Lodève, l'abbé de Lézat et les seigneurs d'Autervie et de La Bastide-Carlipat pour les Etats provinciaux ligueurs [Devic et Vaissète, Histoire générale de Languedoc..., t. XI, p. 845].

${ }^{63}$ Henri duc de Joyeuse, comte du Bouchage, maréchal (1596) : entré chez les capucins (frère Ange) lors de son veuvage et après une vie mondaine à la cour d'Henri III, il devint toutefois lieutenant général et gouverneur pour la Ligue en Languedoc en octobre 1592 suite à la mort de son père et de son frère ; maintenu lieutenant général du roi en Languedoc en vertu de l'Edit de Folembray (24 janvier 1596), il vécut en Languedoc jusqu'à sa retraite au couvent des Capucins en février 1599.
} 
garde qui s'était illustrée depuis 30 ans faisait le choix de quitter la place ${ }^{64}$. La lassitude face à la guerre l'emporta sur l'engagement confessionnel, y compris dans le milieu qui jusque-là avait fait le choix de la radicalité. Le coup de force ultra-catholique réussit un temps grâce à l'autorité d'Henri de Joyeuse, mais la scission du Parlement fut fatale à la cause ligueuse qui ne put empêcher la signature de la paix de Folembray à la fin du mois de janvier $1596^{65}$. Le consensus toulousain qui s'était fissuré à partir de 1589 fut ainsi définitivement rompu en 1595, provoquant une évolution dans les priorités politiques de la cité : il fallait penser à présent à la réconciliation avec le souverain, tout en défendant l'exclusivisme catholique toulousain. Dès lors, les membres modérés du Parlement revinrent dans Toulouse, le roi plaça plusieurs de ses hommes aux postes clefs des institutions urbaines et l'histoire qui commença fut celle d'une récupération politique par les milieux royalistes de l'autorité sur la cité.

Dans le cas de Toulouse, les guerres de Religion furent le théâtre du développement saccadé d'un milieu urbain attaché à l'exclusivisme catholique à l'heure où se posait la question de l'altérité confessionnelle. La politique citadine fut d'abord le fait d'une lutte de factions qui mêlèrent clivages traditionnels et affrontements catholico-protestants dans un projet de contrôle de la cité. A ce jeu, l'intransigeance catholique se révéla par la violence, l'emporta et réussit par cet événement fondateur à imprimer une marque durable sur la destinée de la ville. Elle réussit également à donner l'impression d'un consensus urbain derrière la cause romaine, consensus construit à coup de violences ciblées et de coopération institutionnelle entre les divers lieux de pouvoir citadin. Sous les voûtes du palais du Parlement, dans la salle commune de l'Hôtel de ville, au sein des maisons bourgeoises aussi bien que dans la rue, tous semblent avoir parlé d'une même voie pour condamner l'hérésie et se battre derrière le Christ. L'enchaînement factuel de l'histoire toulousaine conduirait à ne concevoir la cité que dans une unique ligne politico-religieuse, celle du combat papiste contre l'hérétique, déterminisme religieux inéluctable et triomphant de toutes ses confrontations. Evidemment les faits sont trompeurs ainsi que les sources institutionnelles qui ont accaparées la mémoire municipale. Il y eut probablement débat au-delà de la sinistre année 1562, débat dont les violences soudaines de 1572 et 1589 donnent un mince aperçu. Mais il n'atteignit quasiment plus la place publique passé le 17 mai 1562, et fut limité à un mouvement marginal peu influent sur la cité. A la lecture des événements toulousains, nait alors le sentiment d'une intransigeance catholique omniprésente et inévitable, comme si la ville était tombée dans une spirale incontrôlable déterminant l'action municipale vers toujours plus de radicalité, toujours plus de sainteté, toujours plus de violence contre un monde hostile qui courrait à sa perte. Le cheminement de l'intransigeance à Toulouse fut alors celui d'une utopie religieuse imposée par une minorité, acceptée avec plus ou moins de résignation par la majorité, dans le respect d'un cadre institutionnel citadin voué entièrement à son édification. La ville devait tendre par toutes ses composantes au modèle idéal d'une catholicité militante et combattante. Le triomphe de cette vision utopique se réalisa au cours de l'année 1589, dans une ferveur collective et violente adressée à son Eglise plutôt qu'à son souverain. Les conséquences politiques de cette ultime étape dans la radicalité urbaine furent à l'origine de sa perte, parce que la ville finit par redécouvrir ses propres contingences derrière ses idéaux de croisade : une guerre de plus en plus chère, des chefs provinciaux cherchant à contrôler la cité et un souverain prêt à négocier pour pacifier son royaume dans un rapport roi/bonne ville que Toulouse avait toujours aimé entretenir. Le triomphe ligueur fut alors trop violent pour les institutions urbaines et son architecture sociale, si bien qu'il se solda politiquement par une soumission. Néanmoins, cette soumission fut un nouveau départ, celle d'une dissociation mémorielle entre d'une part la légitimité du combat catholique et l'erreur de la rébellion contre son roi. Si la mémoire du crime de lèse-majesté fut rapidement oubliée et

\footnotetext{
${ }^{64}$ Carole Delprat, "Les magistrats du Parlement de Toulouse...", op. cit., p. 59.

${ }^{65}$ Bibl. nat. France, F-46898 (3) : Edit du roi sur la reduction de la ville de Tolose et autres villes du pays de Languedoc et ressort du Parlement dudict Toulouse, Lyon, Thibaud Ancelin, 1596, 32 p.
} 
combattue, celle de l'intransigeance continua pour au moins deux siècles à façonner l'identité toulousaine. 